\title{
Do Ethicists and Political Philosophers Vote More Often Than Other Professors?
}

\author{
Eric Schwitzgebel • Joshua Rust
}

Published online: 1 December 2009

(C) The Author(s) 2009. This article is published with open access at Springerlink.com

\begin{abstract}
If philosophical moral reflection improves moral behavior, one might expect ethics professors to behave morally better than socially similar non-ethicists. Under the assumption that forms of political engagement such as voting have moral worth, we looked at the rate at which a sample of professional ethicists - and political philosophers as a subgroup of ethicists — voted in eight years' worth of elections. We compared ethicists' and political philosophers' voting rates with the voting rates of three other groups: philosophers not specializing in ethics, political scientists, and a comparison group of professors specializing in neither philosophy nor political science. All groups voted at about the same rate, except for the political scientists, who voted about $10-15 \%$ more often. On the face of it, this finding conflicts with the expectation that ethicists will behave more responsibly than non-ethicists.
\end{abstract}

What is the relationship between philosophical moral reflection and real-world moral behavior? Does reflecting philosophically on moral questions lead us to act better? Though the question is central to both moral psychology and moral education, it has never been systematically explored. In this and related articles we plan to make a start.

Electronic supplementary material The online version of this article (doi:10.1007/s13164-009-0011-6) contains supplementary material, which is available to authorized users.

E. Schwitzgebel $(\bowtie)$

Department of Philosophy, University of California at Riverside, Riverside, CA 92521-0201, USA

e-mail: eschwitz@ucr.edu

J. Rust

Department of Philosophy, Stetson University, Unit 8250, 421 North Woodland Boulevard, DeLand, FL 32723, USA

e-mail: jrust@stetson.edu 
Certain practices and institutions seem to operate on the assumption that philosophical moral reflection tends to have a positive impact on moral behavior. Philosophical courses in medical, legal, and business ethics are required, presumably, in part on the assumption that philosophical reflection on those applied moral issues will, down the road, help improve the behavior of budding doctors, lawyers, and tycoons. Philosophers interested in doing what's right - for example, in deciding whether to become vegetarian or whether to go through the trouble of voting on election day-sometimes reflect philosophically, considering consequences, virtues, or the universalizability of maxims, apparently under the assumption that such reflection will help guide them toward the good. Although the value of such reflective practices doesn't strictly require that philosophical moral reflection tends to improve moral behavior - for example, there might be better and worse ways of reflecting, producing a net neutral result - the general acceptance of such practices at least invites that supposition (a supposition apparently shared by Aristotle, Kant, and Mill, among others: Aristotle 4th c. BCE/1962, 1103b; Kant 1785/1998, 4:404-5; Mill 1859/2003, ch. 2). If philosophical moral reflection has no tendency to further the aim of acting well, that problematizes the role of such reflection in everyday life.

Both real-world moral behavior and genuine philosophical moral reflection are recondite, difficult to control, and (as targets of study) fraught with methodological peril. Their relationship, therefore, is difficult to examine. Psychologists have put forward models according to which explicit moral reasoning of the sort encouraged by philosophers either stands near the center of morality (e.g., Kohlberg 1984) or serves mainly to rationalize moral intuitions arrived at prior to reflection (e.g., Haidt 2001), but direct empirical evidence is thin and the question remains wide open. One potential line of evidence that remains untapped is the moral behavior of ethics professors. If philosophical reflection does promote moral behavior, either generally speaking or in a broad range of cases, one might expect that philosophers, especially moral philosophers, would tend to behave better than other people, since presumably they are both prone to such reflection and skilled at it.

The best way to determine the moral impact of a lifetime's philosophical reflection on ethics would be to randomly assign children either to careers in ethics or to other academic careers, then measure their virtue in adulthood using a moralometer. However, since the moralometer has yet to be invented, and since random assignment to careers would require an authoritarian dystopia, we'll have to settle for more modest questions and more limited measures - which we believe can collectively illuminate the broader issues. The present study begins with the assumption that forms of political engagement such as voting have moral worth, and examines the voting frequency of four groups of professors: ethicists (including political philosophers as a subgroup), philosophers not specializing in ethics, political science professors, and a comparison group of professors from other departments. The key question is, do ethicists and political philosophers execute this civic duty more reliably than other professors?

We assume that most ethical theories imply that participation in a representative democracy, including voting in public elections, is in general morally preferable to nonparticipation. John Stuart Mill writes glowingly of the moral benefits that flow from political participation (1861/2006). Aristotle envisions political involvement as an 
important part of the virtuous life (4th c. BCE/1962, 4th c. BCE/1998). Although Kant himself is not entirely clear on the value of representative democracy (1795/1996), more recent deontologists endorse the value of participation and voting. Rawls, for example, writes that citizens are "expected to vote" and that even independently of its direct contribution to justice, voting "leads to a larger conception of society and to the development of... intellectual and moral faculties" on which the "stability of just institutions depends" (1971, p. 234). We recognize, of course, that some people have excellent reason not to vote either in general or on particular occasions and that the question of whether voting is a duty, or whether it is contrary to rational choice theory, or both, is a topic of debate among political scientists and political philosophers (e.g., Downs 1957; Ferejohn and Fiorina 1974; Parfit 1984; Lomasky and Brennan 2000). However, we suspect that most cases of non-participation represent a choice of individual goods over societal ones - a small moral failure in conscientious citizenship, a failure perfectly compatible with moral excellence in many other respects but a failure nonetheless. If philosophical moral reflection has a positive impact on moral behavior, then, one might predict that ethicists, perhaps especially political philosophers (who in the U.S. tend to reflect on and prize democratic institutions), would vote more often than non-ethicists of similar social background.

Of course morality and immorality are too diverse, multi-faceted, covert, situationally malleable, and contentious to be captured by a single measure or even a small group of measures. So this study, considered alone, can illuminate only a small corner of the larger question motivating this research. We do not pretend that conscientiousness in voting is by itself an accurate index of overall moral behavior (especially given the concerns of "situationists" in social psychology such as Ross and Nisbett 1991; Doris 2002). We do hope, however, that a diverse range of studies, viewed jointly, may reveal an overall pattern. Voting is therefore just one measure among several we are exploring to assess the relationship between the professional study of ethics and everyday moral behavior - others include looking at the rates at which ethics books are missing from academic libraries (Schwitzgebel 2009), rates of donation to charity (Schwitzgebel and Rust in preparation), peer assessments of overall moral behavior (Schwitzgebel and Rust forthcoming), and responsiveness to email queries from undergraduate students (Rust and Schwitzgebel in preparation).

Among moral behaviors, voting is particularly amenable to study for two reasons: First, it's a matter of public record whether a person has voted, so we needn't rely on self-report or direct observation. The latter are methodologically problematic, especially regarding the moral behavior of as sophisticated and sparsely distributed a group as professional ethicists. And second, for the U.S. professors who are the target of this study, the opportunity to vote is presumably equally distributed among the comparison groups, eliminating a variety of potential confounds.

In casual conversation, most of the people we've spoken to-although interestingly few political scientists - predicted that political scientists would vote more often than other professors. People were more divided about what to expect from ethics professors. A majority, perhaps, expressed the view that ethicists would be no more conscientious in this matter than other professors. This skepticism mirrors the more general skepticism about the behavior of ethicists we've found in other research (Schwitzgebel and Rust forthcoming). We aim to see if this skepticism is justified, at least with respect to voting. 
Existing studies of professors' voting rates are old and either very limited or based on self-report, and none look at ethicists or political philosophers specifically (Joyner 1963; Yee 1963; Turner and Spaulding 1969; Turner and Hetrick 1972; Creason 1978; Roettger and Winebrenner 1983). Although both psychologists and philosophers sometimes discuss the relationship between moral reflection and moral behavior (in psychology, see Kohlberg 1984; Haidt 2001; and the reactions to them; in philosophy, see Plato's Apology, Protagoras, and Meno in 4th c. BCE/1997; Aristotle 4th c. BCE/1962; Kant 1785/1998; Mill 1859/2003; Moody-Adams 1997; Nussbaum 1997, 2007; Posner 1999), we are aware of no published empirical studies of the moral behavior of ethicists.

\section{Method}

We compiled lists of professors from university websites in five U.S. states: California, Florida, Minnesota, North Carolina, and Washington State. We chose these states for the ease of access to public voting records-records of whether individuals have voted, not how they have voted-and the large number of universities not near the borders of other states. We categorized philosophers as ethicists or non-ethicists based on area of specialization information as found on philosophy department websites. (Philosophers not listing specialization or who specialized in philosophy of religion or philosophy of action but no other ethicsrelated area were counted neither as ethicists nor as non-ethicists.) About half of all philosophers indicated a specialization in ethics or a subfield of ethics. We collected samples of political scientists and other professors from political science department websites and online faculty directories at the same universities, so that the four main comparison groups (ethicists, non-ethicist philosophers, political scientists, and other professors) were all about the same size and drawn proportionately from the same universities. We also noted academic rank (when listed) and whether the professor was in a research- or teaching-oriented university. (For further methodological details, see the on-line Appendix.)

We assessed the voting history of each professor by looking for name matches between the faculty lists and public voting records of people residing within 60 (or in some cases 50) miles of the university. We excluded from analysis professors with more than one name match. (This amounted to $14.3 \%$ of the listed faculty, with very similar rates of exclusion among the four groups: $\chi^{2}, p=.99$.) Below, we will discuss the possible effects of false matches. When a match was found we also noted, when available from the public records, the voter's birth year, gender, ethnicity, and political party. (Again, for details, see the methodological Appendix.)

Not all locations provided equally detailed voting histories (California, in particular, only provided data for statewide elections), nor were voting opportunities the same in every location. However, since we balanced the data so that approximately the same number of ethicists, non-ethicist philosophers, political scientists, and other professors were drawn from each university, we assume that local differences wash out; state-by-state differences we will examine below. Our primary analysis considers professors' votes per year starting with the year 2000, or the first year in which a vote is recorded if that year was later than 2000, and 
extending through late 2007 or early 2008, depending on state (in no case including the 2008 Presidential primary election). While the 2000 cutoff date is arbitrary, it reflects the fact that some regions' voting history records extend only back into the late 1990s.

We recognize that there are some shortcomings in these data: The selection of states may be unrepresentative (the Northeast, for example, is not included); we don't have information about differences in voting opportunities especially in local elections; and the attempt to match professors' names with names in voter rolls necessarily produces some overmatches that have to be discarded as well as some mismatches. This study is archival, labor-intensive, and limited by available data. However, it is in our view clearly superior to relying on self-report (as nearly all previous studies of professors' voting behavior have done), since it seems to us likely that pressures distorting self-reports are likely to vary between the groups and thus be confounded with the variable under study.

\section{Results}

Overall Voting Rates Overall voting rates by group are shown in Table 1. (These data include only professors for whom we found a voting history with at least one recorded vote; for discussion of those with no voting record, see below.) The main result of our analysis is this: Political scientists voted somewhat more frequently than other professors (about 10-15\% more frequently), while all other groupsincluding ethicists and political philosophers - voted at about the same rate. In fact the trend among tenure-track professors was for ethicists and political philosophers to vote a little less than the other groups (though the differences in voting rates among these groups remained within the range of chance variation). In other words, the data suggest that civic engagement as measured by voting frequency is no higher among ethicists, including political philosophers, than among professors in general.

Table 1 Mean recorded votes per year by area of specialization; numbers in parentheses include tenuretrack professors only

\begin{tabular}{lcc}
\hline group & $\begin{array}{l}\text { mean recorded } \\
\text { votes/year }\end{array}$ & $\begin{array}{l}\text { \# of profs with one } \\
\text { voter match }\end{array}$ \\
\hline PHILOSOPHERS & $0.98(0.97)$ & $562(444)$ \\
$\quad$ non-ethicists & $1.04(1.01)$ & $221(186)$ \\
ethicists & $0.98(0.95)$ & $265(204)$ \\
$\quad$ political philosophers & $0.99(0.96)$ & $112(90)$ \\
$\quad$ other ethicists & $0.95(0.94)$ & $153(114)$ \\
POLITICAL SCIENTISTS & $1.09 *(1.10 *)$ & $316(265)$ \\
OTHER PROFESSORS & $0.93(0.98)$ & $283(198)$ \\
\hline
\end{tabular}

Asterisks indicate a significant difference (by planned two-tailed $t$-tests) from the "other professors" group at an alpha level of .01; ANOVA of ethicists, non-ethicists, political scientists, and other professors, $p<.001$ 
Before we can draw this conclusion confidently, however, we need to examine the data for a number of potential shortcomings and confounds. To anticipate: We find no problems that undermine the main result.

Skew The data are somewhat right-skewed (with the majority of individuals in the 0.25-1.00 range and a minority trailing off into twice a year or more). To correct for this, we use the positive square root of vote rate for all parametric statistical analyses. The main findings are the same either way.

Differences by State Due to differences in voting opportunities and state recordkeeping, we found more recorded votes per year for professors in Washington State than in the other four states. Mean votes per year in Washington was 1.38; in California, Florida, Minnesota, and North Carolina mean votes per year were 0.96, $0.95,0.93$, and 0.88 respectively (ANOVA $p<.001$; Tukey pairwise comparisons finds WA significantly higher than all other states and CA significantly higher than NC only). This introduces a potential confound into the data, since although we matched the number of philosophers in every university with approximately half as many political scientists and other professors at the same university, it was not possible to control the distribution of ethicists and non-ethicists within philosophy in the same way; and as it happens, ethicists and non-ethicists were not equally distributed among the states $\left(\chi^{2}=.02\right.$; see Table 3 in the Appendix for raw numbers), with California having the lowest ratio of ethicists to non-ethicists (0.88) and Washington State the highest (1.71). However, this does not undermine our findings. As we will note below, regression analyses accounting for state yield the same result as the main analysis described above. Furthermore, since Washington State had the highest vote rate, correcting for the uneven distribution should only make stronger our overall finding that ethicists voted no more often than non-ethicists.

Ceiling Effects in California We drew almost half our sample from California, for which we only have data for statewide elections. Professors' voting rates in these elections were high by U.S. standards. Among California professors in our database who were registered to vote in the June 2006 primary election, $60 \%$ voted, compared to $33.6 \%$ of registered voters statewide (source: http:/www.sos.ca.gov/elections); among those registered to vote in the November 2006 general election, $82 \%$ voted, compared to $56.2 \%$ statewide. Indeed, looking at the six statewide elections in our data set beginning with 2003, among California professors whose first recorded vote was in 2003 or earlier, $52 \%$ of those on our lists voted in all six elections, and $72 \%$ voted in at least five of the six. Since a majority of professors who voted at all voted in virtually every statewide election, it's possible that ceiling effects are flattening the California data and obscuring potential differences: Ultra-conscientious voters would look the same in our California database as professors with fairly ordinary professorial habits. However, this possible flattening cannot explain our overall findings. Excluding California does not alter the results of our analysis: Political scientists remain a group apart, while the other groups all voted at essentially the same rate (ANOVA, $p<.001$, and planned two-tailed $t$-tests at an alpha of .01). Since the other four states include data from local elections, which often have low 
participation rates, ceiling effects are not a problem in those states, with the data showing a good spread on the right side.

Variance Among the Groups ANOVA analysis assumes that the groups do not differ in the variance of their scores. We initially thought that political scientists or political philosophers might show a higher variance in vote rates than other professors, since extreme views about the importance or pointlessness of voting may be overrepresented in those groups. However, the variance in the square roots of the vote rates is virtually identical among the four main groups (pooled $s^{2}=.052$, Bartlett's test, $p=.90$ ), and also between political philosophers and other philosophers (pooled $s^{2}=.051$, Bartlett's test, $p=.83$ ).

Professors Registered to Vote but with No Recorded Votes Some professors were matched with a registered voter with no recorded votes. This might reflect recent registration, failure of the state to match the record with a record at a previous address, a gap in the data, or a pattern of not voting, and thus is difficult to interpret. Therefore, these data were excluded from analysis. Fortunately, the rates of name match with no recorded votes were small and similar among the four groups $(6.2 \%$ overall, $\left.\chi^{2}, p=.60\right)$ and so unlikely to be driving any effects. Adding these professors into the analysis with a vote rate of zero does not change the main findings.

Professors with No Voting Record Found It's also hard to interpret cases in which no voting record is found. The person may be a non-voter, but she may instead be registered to vote under a different name or in a different location, or she may have recently moved, or she may be a non-citizen or felon and so prohibited from voting. Nonetheless, it seems desirable to see if the four groups differed in percentage of professors with no record found. Table 2 presents these results. The difference between the groups is not statistically significant $\left(\chi^{2}, p=.14\right)$.

We further examined the trend for non-ethicist philosophers to have fewer records found than ethicists (two-tailed two-proportion $z$-test, $p=.02$, treating the $\mathrm{p}$ value cautiously since the $\chi^{2}$ is not significant). Post-hoc analysis reveals this difference to be driven almost entirely by professors at research universities (which have a higher proportion of non-ethicists than do other universities: $39 \%$ vs. 60\%, twotailed, two-proportion $z$-test, $p<.001)$. We then checked these research professors' professional and department pages for evidence of excusers from voting. We found that more than three quarters of the research professors with no matching voter record were either appointed fewer than two years before the data collection

Table 2 Percentage of professors with no voting record found under their name within 60 miles of their university (in FL, MN, and WA 50 miles: see Appendix)

\begin{tabular}{lcc}
\hline group & \# with no record found & $\%$ with no record found \\
\hline ethicists & 104 & $22.4 \%$ \\
non-ethicist philosophers & 125 & $29.1 \%$ \\
political scientists & 150 & $26.2 \%$ \\
other professors & 138 & $26.9 \%$ \\
\hline
\end{tabular}


(i.e., after 2005), showed evidence of a foreign background, were dead, or were at least part time in another location. Excluding those faculty eliminates the difference between ethicists and non-ethicist philosophers. It also suggests that within two years of moving to a new location over $90 \%$ of philosophers at research institutions who are eligible to vote do register to vote - an impressively high rate compared to overall U.S. voter registration rates $(68 \%$ of eligible adults in 2006 , according to the U.S. Census Bureau; source: http:/www.census.gov/population/www/socdemo/ voting.html).

Academic Rank Academic rank is a confounding variable. Academic rank correlates with voting rate (using non-tenure track, Assistant Professor, Associate Professor, and full Professor as four ranked categories, $\rho=0.18, p<.001)$, and the four main groups differ in the distribution of academic ranks $\left(\chi^{2}, p<.001\right)$, mainly because the "other professors" category has a lower percentage of tenure-track faculty. (This may reflect either a real difference in rank distribution or a tendency for non-tenure track faculty to be listed in university directories at a higher rate than on departments' websites.) To correct for this, we excluded from analysis non-tenure-track faculty and faculty with no rank indicated. With this exclusion, there is no statistically detectable difference in rank between the four main groups $\left(\chi^{2}, p=.06\right.$, with a trend toward higher rank among philosophers). The results of the analysis are virtually the same as without the exclusion: See the parenthetical data in Table 1. However, because of this confound, the remaining analyses include only tenure-track professors.

Age, Ethnicity, Gender, and Political Party Political scientists have generally found that older people, Caucasians, women, and Republicans vote more frequently than younger people, ethnic minorities, men, and Democrats (see Abramson et al. 2007; http://www.census.gov/population/www/socdemo/voting.html). Fortunately, none of these variables appear to confound our data. In contrast with the national data, the male and female professors on our lists voted at the same rate (square root of rate 0.98 vs. 0.98 , two-tailed $t$-test, $p=.82$ ), as did Democrats and Republicans (0.98 vs. 0.96, two-tailed $t$-test, $p=.40$, no data from Minnesota or Washington State). Therefore, although the distributions of women and Republicans differed among the four groups $\left(\chi^{2}, p=.002, p=.006\right.$; with non-ethicist philosophers both the most male and the least Republican), those differences are unlikely to be distorting our findings.

In accord with national data, older professors voted more frequently than younger ones $(r=0.14, p<.001)$. Fortunately for our analysis, the four groups did not differ in mean age (ANOVA, $p=.10$, with a trend for political scientists to be younger). Also in accord with national data, self-described ethnic minorities (only North Carolina and Florida provided these data) voted less frequently than self-described non-Hispanic Caucasians (square root of vote rate 0.83 vs. $0.96, p=.03$ ). We have no evidence that ethnicity differs significantly between the groups $\left(\chi^{2}, p=.39\right)$; however, since the number of self-described minorities is tiny-only 26 professors!-we cannot draw definite conclusions.

Incidentally, in accord with research on gender distribution in philosophy (Haslanger 2008), tenure-track philosophers overall were $77 \%$ male, with positive correlations between gender and age $(r=.15, p=.002)$ and gender and rank $(\rho=.16$, 
$p<.001)$. However, a regression predicting philosophers' rank on the basis of age and gender together shows gender to be only marginally predictive of rank $(p=.06)$. Our findings also support the widespread finding that U.S. academics tend to be Democrats (Ladd and Lipset 1976; Klein and Western 2004-5; Gross and Simmons 2007). Among tenure-track philosophy professors with a recorded party affiliation (83.6\% of professors matched with voting records in CA, FL, or NC), $88 \%$ were Democrats, $7 \%$ were Republicans, and 5\% identified with a minor party. Among political scientists the percentages were $80 \%, 14 \%$, and $5 \%$; among the other professors $80 \%, 19 \%$, and $2 \%$.

Institution Type Professors at research-oriented institutions voted at the same rate as professors at teaching-oriented institutions (square root of rate 0.99 vs. $0.97, p=.39$ ), so although a smaller percentage of philosophers at research institutions were ethicists than at teaching institutions (39\% vs. 60\%, two-tailed two-proportion $z$-test, $p<.001$ ), this difference, too, is unlikely to be affecting the comparisons.

Name Frequency and City of Residence We were concerned that there may be a substantial number of false matches - cases with no local voting record for the professor but a voting record for exactly one other person of the same full first and last name (and middle initial or name when known) within 60 miles of the university (or in some cases 50 miles; see Appendix). To test the possibility that false matches may be driving the results, we compared the voting rates of professors with common names and those with rare names (those names such that only one voter in the state had that last name and first initial), on the assumption that false matches would be less likely for professors with rare names. Professors with rare names were slightly more likely to vote than those with common names (square root of rate 1.00 vs. 0.97 , two-tailed $t$-test, $p=.04$ ). Since voting rates among professors are considerably higher than in the general population, this result is consistent with occasional false matches dragging down the voting rates of professors with common names. However, since the effect size is small and since the groups did not differ in the distribution of common names $\left(\chi^{2}, p=.38\right)$, it's unlikely that false matches are having much effect on the main comparisons. Very similar remarks apply to the comparison between professors with their name matches in the same city that houses the university and those with their name matches in farther cities (square root of rate 1.00 vs. $\left.0.95, p=.006, \chi^{2}, p=.19\right)$.

Multiple Regression A standard multiple regression analysis accounting simultaneously for all the potentially confounding factors discussed above is not possible due to the fact that the great majority of records have at least one missing data point. However, enough data exist for a meaningful regression analysis that takes into account age, academic rank, gender, institution type, state of residence (treating California as the reference group and excluding North Carolina which did not provide age data), and group (treating the "other professors" as the reference group). Confirming our main analysis, specialization in political science is a significant predictor (coefficient $=.065, p=.003$ ) and specialization in ethics and specialization in non-ethics philosophy are not predictive $(p=.77, p=.18)$. Also predictive is residence in Washington State (coefficient $=.188, p<.001)$, birth year $($ coefficient $=-.0030$, 
$p<.001$ ), and academic rank (coefficient $=.022, p=.008$ ), but not institution type, gender, residence in Florida, or residence in Minnesota. A separate regression excluding age and including North Carolina yields similar results, with residence in North Carolina negatively predictive (coefficient $=-.044, p=.04$ ).

\section{Conclusion}

Ethicists and political philosophers vote no more often than other professors. Apparently, neither the general philosophical moral reflection practiced by ethicists nor the more particular philosophical reflection about democratic institutions practiced by U.S. political philosophers has a positive influence on voting frequency. The latter is especially striking in light of our finding that political scientists vote more frequently than other professors. Political scientists presumably vote more frequently either because of a greater sensitivity to citizens' responsibility to vote or because of a greater personal interest in politics (either of these might be either a cause or effect of specialization in political science); one might have thought that political philosophers would share those tendencies.

We also find it interesting that all the groups under study showed the same variance in voting rates. We had expected that there would be a wider spread of views about the value of voting among political scientists and political philosophers than among other professors. Either there is no such wider spread of views or that wider spread of views does not reveal itself in actual voting behavior.

We hope that the results of this study, when combined with other results, will help clarify the relationship between moral reflection and moral behavior. The simplest interpretation of this study is that moral reflection has no effect on behavior. However, we hesitate to draw this conclusion. It may be that we are wrong about the moral importance of voting regularly. It may be that voting behavior correlates poorly with overall moral behavior. (Probably so. But we doubt any tractable measures for this population correlate much better, which is why we aim for multiple measures.) As we continue to collect data, we hope a general pattern will emerge. Perhaps we will find ethicists to behave better, but only on a narrow range of practical issues very tightly related to their professional interests; or perhaps a certain amount of philosophical moral reflection proves beneficial while too much proves harmful. It may turn out that people drawn to careers in ethics profit from philosophical moral reflection but have a counterbalancing lack of other prods to moral behavior. Philosophical moral reflection might prove virtually inert, or it might provide a random push away from conventional morality, or it might prove morally helpful in some contexts and harmful in others. The theoretical possibilities are various. Given the paucity of data, we think it premature to draw general conclusions.

Acknowledgements We gratefully thank Anjelique Stevenson-Taylor for her long hours coding these data, as well as the numerous people who have given us feedback on this project both in person and on the Splintered Mind blog (http://schwitzsplinters.blogspot.com/), especially Martin Johnson, Peter Hanks, and the UC Riverside Statistical Collaboratory. This project would not have been possible without staff support from the Philosophy Department at Stetson University and technical help from CHASS College Computing at UC Riverside. 
Open Access This article is distributed under the terms of the Creative Commons Attribution Noncommercial License which permits any noncommercial use, distribution, and reproduction in any medium, provided the original author(s) and source are credited.

\section{References}

Abramson, P.R., J.H. Aldrich, and D.W. Rohde. 2007. Change and continuity in the 2004 and 2006 elections. Washington: CQ.

Aristotle 4th c. BCE/1962. Nicomachean ethics (trans: Oswald, M.). New York: Macmillan.

Aristotle 4th c. BCE/1998. Politics (trans: Reeve, C.D.C.). Indianapolis: Hackett.

Creason, N. 1978. Registration and voting participation of four faculty groups. Nursing Research 27: 3257.

Doris, J.M. 2002. Lack of character. Cambridge: Cambridge University Press.

Downs, A. 1957. An economic theory of democracy. New York: Harper and Row.

Ferejohn, J.A., and M.P. Fiorina. 1974. The paradox of not voting: A decision theoretic analysis. American Political Science Review 68: 525-536.

Gross, N., and S. Simmons. 2007. The social and political views of American professors. Manuscript.

Haidt, J. 2001. The emotional dog and its rational tail: A social intuitionist approach to moral judgment. Psychological Review 108: 814-34.

Haslanger, S. 2008. Changing the ideology and culture of philosophy: Not by reason (Alone). Hypatia 23: 210-23.

Joyner, C. 1963. Political party affiliation of University Administrative Teaching Personnel. Southwestern Social Science Quarterly 43: 353-6.

Kant, I. 1785/1998. Groundwork of the metaphysics of morals (trans: Gregor, M.). Cambridge: Cambridge University Press.

Kant. I. 1795/1996. Toward perpetual peace: A philosophical sketch. (trans: Colclasure, D.L.). In Toward perpetual peace and other writings on politics, peace, and history, ed. P. Kleingeld. Binghamton: Vail-Ballou.

Klein, D., and A. Western. 2004-5. Political diversity in six disciplines. Academic Questions 18: 53-65.

Kohlberg, L. 1984. The psychology of moral development. Cambridge: Harper \& Row.

Ladd, E.C., and S.M. Lipset. 1976. The divided academy. New York: Norton.

Lomasky, L.E., and G. Brennan. 2000. Is there a duty to vote? Social Philosophy and Policy 17: 62-86.

Mill, J.S. 1859/2003. On liberty. In Utilitarianism and on liberty, 2nd ed, ed. M. Warnock. Malden: Blackwell.

Mill, J.S. 1861/2006. Considerations on representative government. Ann Arbor: University of Michigan Library.

Moody-Adams, M.M. 1997. Fieldwork in familiar places. Cambridge: Harvard.

Nussbaum, M.C. 1997. Cultivating humanity. Cambridge: Harvard.

Nussbaum, M.C. 2007. On moral progress: A response to Richard Rorty. University of Chicago Law Review 74: 939-60.

Parfit, D. 1984. Reasons and persons. Oxford: Oxford University Press.

Plato 4th c. BCE/1997. Complete works, ed. J.M. Cooper. Indianapolis: Hackett.

Posner, R.A. 1999. The problematics of moral and legal theory. Cambridge: Harvard.

Rawls, J. 1971. A theory of justice. Cambridge: Harvard.

Roettger, W.B., and H. Winebrenner. 1983. The voting behavior of American Political Scientists: The 1980 presidential election. Western Political Quarterly 36: 134-48.

Ross, L., and R.E. Nisbett. 1991. The person and the situation. Philadelphia: Temple.

Rust, J., and E. Schwitzgebel. In preparation. The moral behavior of ethics professors: Responsiveness to student emails.

Schwitzgebel, E. 2009. Do ethicists steal more books? Philosophical Psychology 22: 711-25.

Schwitzgebel, E., and J. Rust. Forthcoming. The moral behavior of ethicists: Peer opinion. Mind.

Schwitzgebel, E., and J. Rust. In preparation. The self-reported moral behavior of ethics professors.

Turner, H.A., and C.C. Hetrick. 1972. Political activities and party affiliations of American Political Scientists. Western Political Quarterly 25: 361-74.

Turner, H.A., and C.B. Spaulding. 1969. Political attitudes \& behavior of selected academically-affiliated professional groups. Polity 1: 309-36.

Yee, R. 1963. Faculty participation in the 1960 presidential election. Western Political Quarterly 16: 213-20. 